\title{
Research on Optimization Design Model of Computer Classroom Teaching Model based on Motivation Theory in Colleges and Universities
}

\author{
Yixin Chen \\ Jianghan University, HuBei, WuHan 430056, China. \\ blairchen@126.com
}

\begin{abstract}
The famous American psychologist Keller put forward the motivation theory of giving the four elements of ARCS (attention, Relevance, Confidence, Satisfaction) by integrating various motivation theories, aiming at stimulating students' attention and establishing student learning information. It gains psychological satisfaction and thus enhances learning interest. Based on the ARCS motivation theory model, this paper puts forward the optimization design model of computer teaching mode in colleges and universities, investigates and analyzes the motivation characteristics of college students, and finds that the current learning motivation is the focus of computer teaching reform in colleges and universities, and the evaluation of the implementation effect of diversified and mufti-angle motivation strategies. The comparison found that students' computer learning motivation and academic achievement have improved, which is worthy of in-depth study by educators.
\end{abstract}

Keywords: Learning motivation; ARCS motivation design pattern; Colleges; Computer teaching.

\section{Introduction}

In order to thoroughly implement the strategic deployment of the central government's education information, the objectives and tasks of education information as defined in the National Mediumand Long-Term Education Reform and Development Plan will be completed, and the information of the 13th Five-Year Plan will be comprehensively and deeply promoted. Work, in order to achieve a networked, digital, personalized, lifelong education system, build a learning society where everyone can learn, learn everywhere, and learn from time to time, and cultivate the development goals of a large number of innovative talents. It is necessary to increase the emphasis on computer education, and computer education is also facing greater challenges. In major universities, the emphasis on students' computer skills has become an important part of the knowledge structure of contemporary college students [1]. After the author's research on computer students' knowledge of computer knowledge, the students have different starting points for computer learning before entering school, and the students' learning and interest in computer knowledge have not been mobilized. In addition, the teaching methods of computer teachers are relatively backward. Leading students' computer skills to a halt. In order to meet the requirements of the development of college education, to improve the level and effect of computer basic education, to enhance students' motivation to participate in computer knowledge learning, to enhance the ability of teachers' teaching design, to get rid of the current teaching effect of teaching and the unsatisfactory quality of teaching, it is necessary to Computer-related courses in colleges and universities carry out reasonable and effective teaching design.

\section{An ARCS Model based on Motivation Theory}

\subsection{Overview of Motivation Theory}

Motivation is a state of mind that causes an individual to act, maintains it, and orients it toward a certain goal. Motivation can effectively arouse a person's behavior. Once the behavior is caused, it needs to be maintained. In order not to cause blind behavior or interruption of behavior, the motivation always points to the specific goal. Motivation, as a state of mind, has stability, but its stability has a unique transient nature. Only by continuously stimulating, improving, and maintaining motivation can an individual's goal be achieved. 


\subsection{Learning Motivation}

The classification criteria for learning motivation vary, but learning motivation has a significant impact on learning process and learning outcomes in learning activities. In the process of learning, the learner's learning behavior can be directed to a specific goal, so that the learner strives to achieve the set learning goal, and the learning motivation has a directional effect on the learner [2]. Learning motivation determines which results can be strengthened, which can adjust and improve learning behaviors, indicating that learning motivation has a regulating effect on learners; learning motivation can make learners focus more on learning behaviors and tend to learn Goals are accomplished in a variety of ways, and learning motivation has the effect of improving the level of learner information processing. In terms of learning outcomes, Yakes and Dodson's Law explains the relationship between learning motivation and learning outcomes, as shown in the following figure.

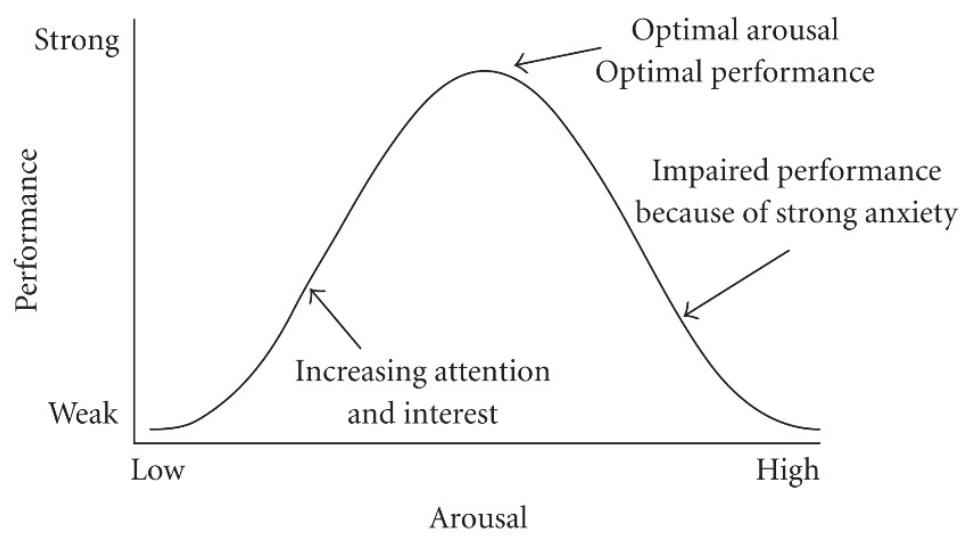

Fig.1 Yakes and Dodson's Law: Learning Efficiency and Motivation Level Curved

\subsection{Overview of the Design Pattern based on ARCS Motivation}

The ARCS motivational design model was proposed by American psychology professor Keller. He synthesized a variety of motivational research perspectives. In 1983, he proposed four elements of the motivational design model: interest, relevance, expectancy, and satisfaction. Later, in his discussion with the graduate student of Sorrah University, he suggested that in order to facilitate the memory, change the interest to Attention and change the expectation to Confidence. In this way, the first letters of the four English words of attention, relevance, confidence and satisfaction are combined into one ARCS mode [3].

The ARCS motivation model can be seen as a process in which to stimulate a person's motivation for learning, to arouse his attention and interest in a study; to make him feel that he is capable of doing this well, and then let him understand to complete this The task is closely related to him first; then to generate confidence; finally let him experience the sense of accomplishment after completing the study, and feel satisfied. This process is a cyclic process, as shown in Figure 2.

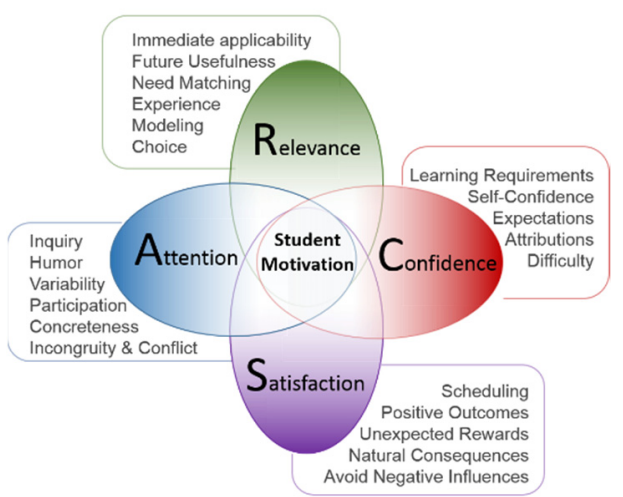

Fig.2 ARCS motivation model 


\section{ARCS-based Computer Teaching Classroom Element Analysis and Teaching Design Process}

\subsection{Design Process of ARCS Design Pattern}

In the related research on the integration of ARCS with teaching process and instructional design, the most admired teaching designers or teachers are the integration of ARCS motivation model and Gagne's nine teaching events. Foreign scholar Cruise has associated four motivational categories in the ARCS motivational design model with the Gagnes nine teaching events.

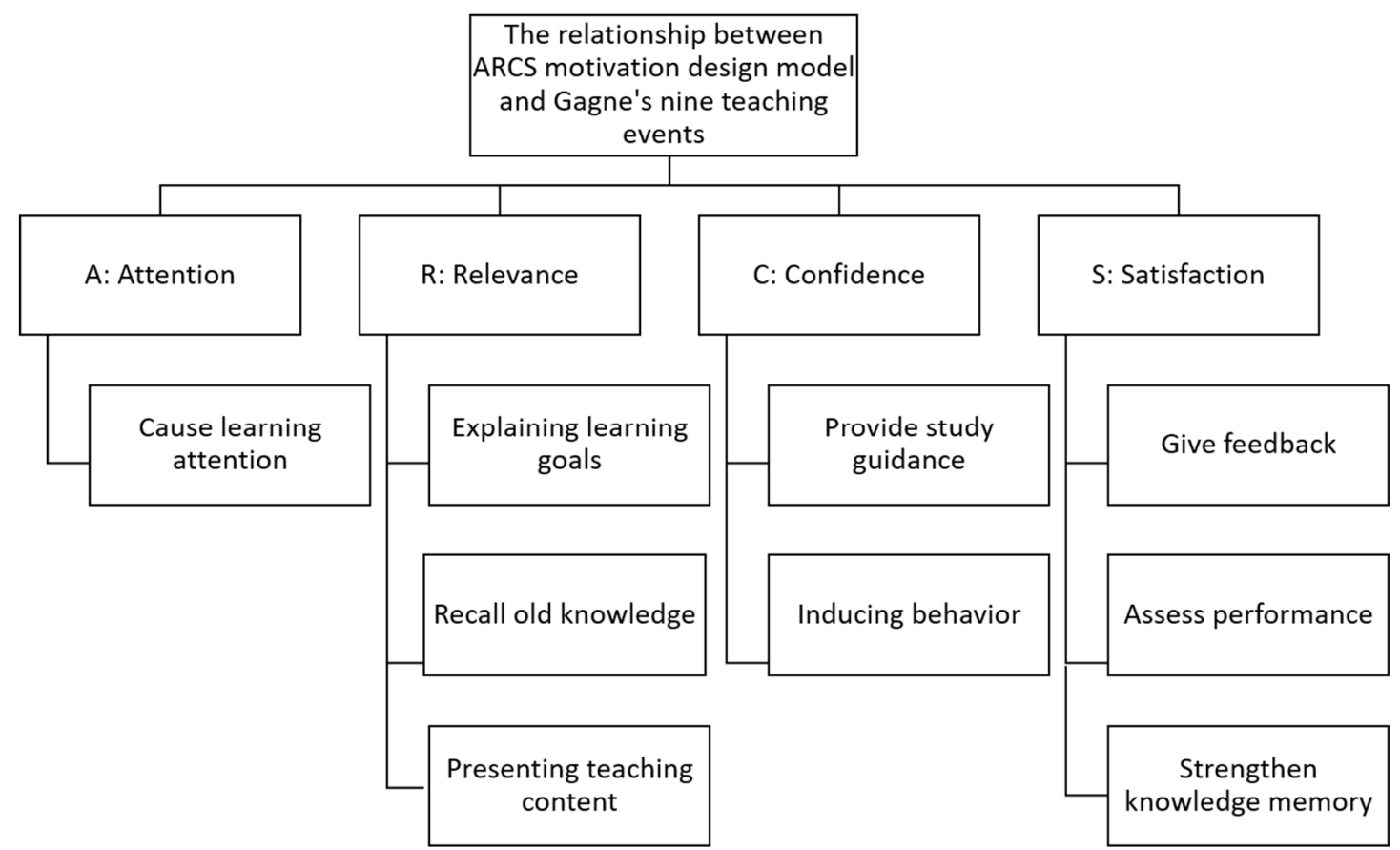

Fig. 3 Relationship between ARCS motivation design pattern and Gagne's nine teaching events

According to Keller's motivation, the ten steps of designing the systematical process and motivation strategy design, the application process of ARCS motivation design mode is shown in Figure 4. In the specific application process, it is divided into four stages, namely the first stage: collection Information and analysis requirements, including the acquisition and analysis of learner information, the acquisition and analysis of course information, and the analysis of textbooks. The second stage: the development of motivational goals, including the development of teaching objectives and evaluation criteria. The third stage: design, application strategy, including design and selection of teaching strategies, combined with teaching activities. The fourth stage: formative evaluation, which includes selection, development of learning materials, evaluation of modified motivation strategies. The final evaluation results in turn provide favorable feedback for the design of the three stages of definition, design and development [4]. 


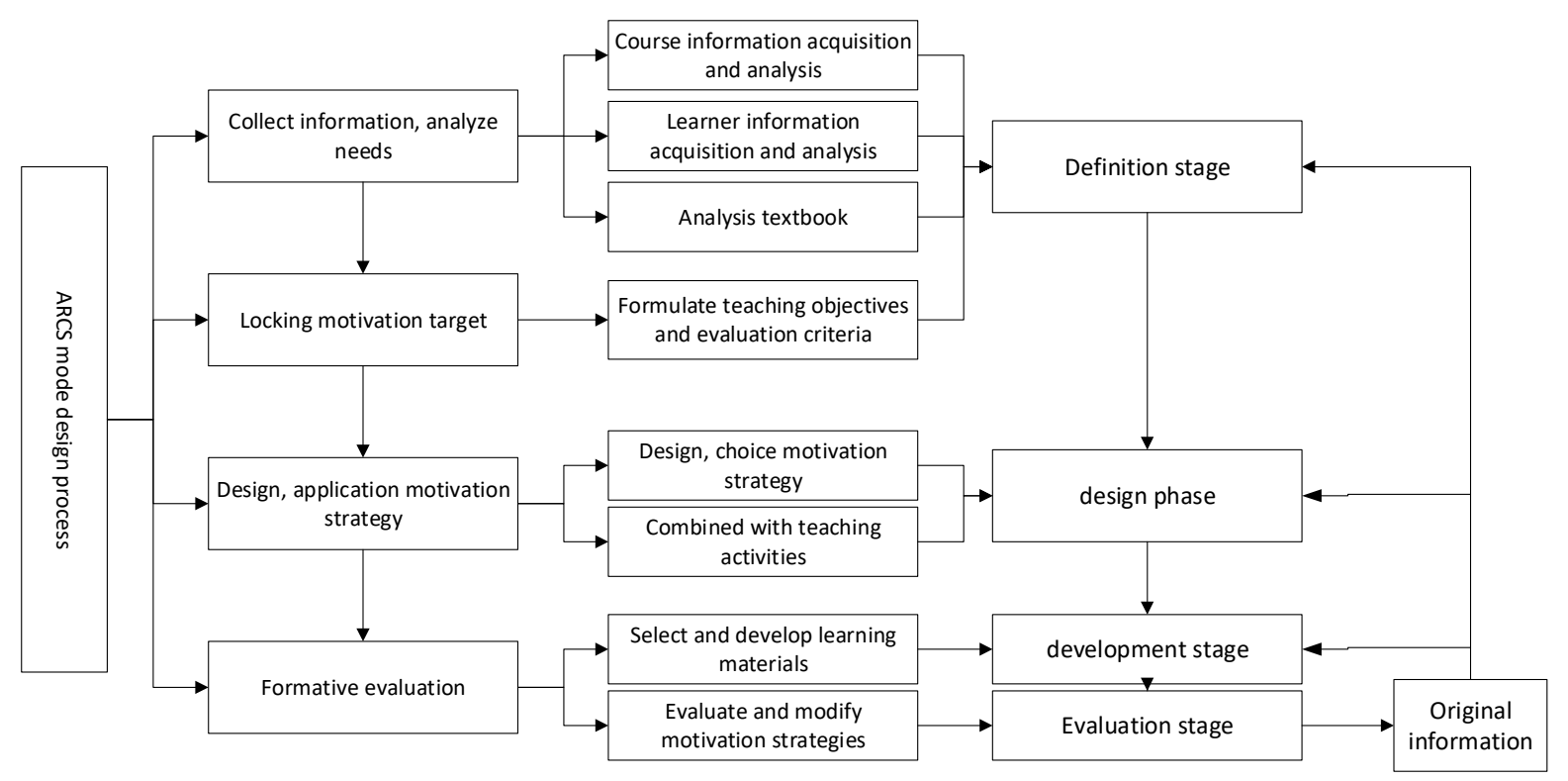

Fig. 4 ARCS mode design process

\section{C language Course Example Design Research Program}

\subsection{Analysis of the Practice Model}

In the teaching process of $\mathrm{C}$ language programming, based on the theory of achievement motivation, it has important guiding significance for teaching. This aspect is due to the need to understand and absorb the curriculum itself. It is necessary to cultivate students' sense of learning achievement in the course of learning this course, especially through such a "language" that can "communicate" with the computer. The technology and ability of computer communication; more importantly, the course is usually the first-level professional course for undergraduate students of computer or software colleges, except for the computer foundation. The students' ability to control the computer will continue to affect the students' other courses. Learn. Even in McClelland's study of the concept of achievement motivation, there is a high correlation coefficient between the social achievement index of the year and the subsequent level of economic development [5]. Stimulating and cultivating the level of achievement motivation of college students not only contributes to the development of individual achievement, but also has a great impetus to the development of society.

\subsection{A Inspire Students to Pay Attention}

When talking about the knowledge points of the loop, why is the concept and content of the loop necessary in the programming, rather than the programming language when talking about the knowledge points of the loop, why the concept and content of the loop is in the programming Required, not programming language design.

Question 1: Calculate the result of $1+2+3+\ldots+100$ ?

When this question is raised, the student usually answers the answer 5050 directly; when asked about the calculation method, after the middle school training, the student's answer is usually based on the calculation of the arithmetic formula of the arithmetic progression. At this time, further ask students, in addition to the calculation method of this formula, is there any other calculation method? This causes students to think. After the training of the formula, the students often form a fixed thinking. At this time, the students' thinking habits are broken. Can you propose that you can add 99 times in total? Bring the student's ideas back to the simplest and most natural calculation method. Because there are many solutions to this problem, it is not too convincing to explain the necessity of the cycle, but this example realizes the transition from the previous knowledge to the ideas learned in this chapter. Based on this, the problem can be further raised. 


\subsection{Looking for Problems Related}

Question 2: Calculate the result of $15+25+35+\ldots+1005$ ?

In the face of this calculation, which is similar to the previous problem, but slightly modified, there is no other solution for the ore-training or summarizing formula for this kind of calculation in the middle school stage. Only the most intuitive ones can be considered. Adding ideas; at the same time, because in the previous example, students have been thinking about adding items one by one when considering similar problems, so by this time, students can naturally accept the method of repeated operations. Further, ask the student how to write based on the knowledge currently learned when performing 99 similar operations for this. Students will definitely say that they want to write 99 additions, and then they will feel unreal. In this example of the teaching process, we first raise the familiar problems of the students, causing the students' thinking and interest; and then guiding the students' ideas [6]. The change of the problem naturally leads to the content to be taught. This can improve students' interest in learning and understanding, improve students' motivation for achievement, and lay a solid foundation for the teaching of specific content. Similar to the process of question extraction, in the specific teaching process of the course content, we must constantly interact with the students in the way of asking questions, maintain the students' attention, and improve the students' achievement motivation in the students' correct answers to the questions. .

\subsection{Shape Students' Self-confidence}

It is precisely because of the importance of students' achievement motivation that teachers need to set their homework in order to meet the students' achievement psychology and expectations, and to set up assignments in an encouraging manner. That is to say, do not assign difficult assignments to students, but should start from the basics, or give ideas or similar examples of procedures, improve the difficulty of the work from shallow to deep, so that students can solve problems in simple topics. Get satisfaction and a sense of accomplishment, increase confidence, and solve more complex problems.

Question 1, how to design a small game in the game. For example, the following is a very beautiful animation program. When the program is running, as shown in Fig.5 (A), the whole screen forms a pear-shaped screen with a small yellow planet in the middle that keeps turning and emitting red light.
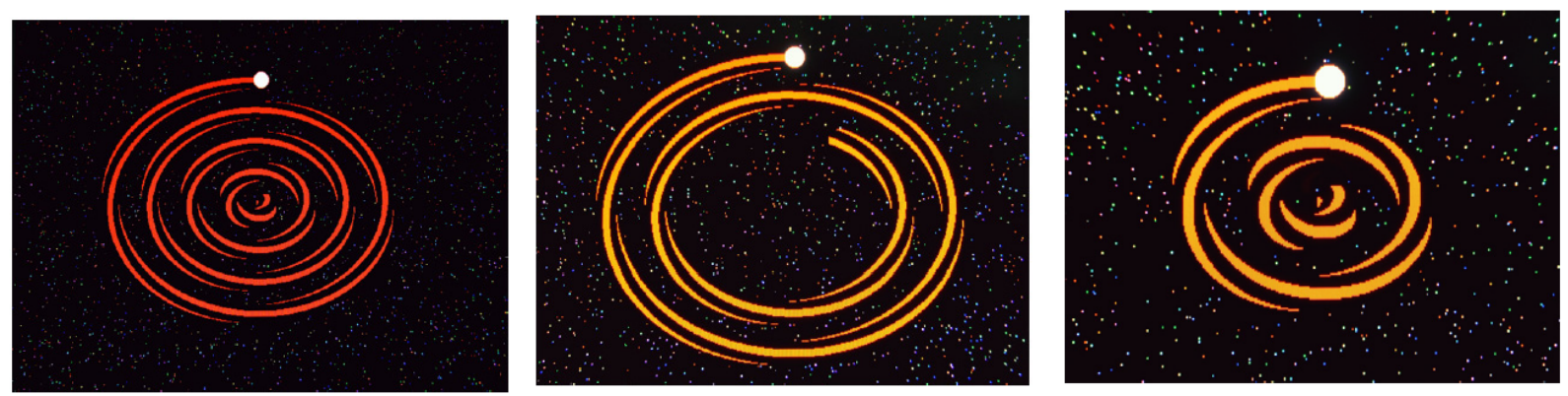

(A) Run image when initial value has not changed

(B) Run the image as soon as the expression changes

(C) Run image when expression two changes

Fig.5 Pear-shaped screen corresponding to different expressions

\#include $<$ graphics.h $>$

\#include $<$ stdio.h $>$

\#include $<$ stdlib.h $>$

\#include $<$ alloc.h $>$

\#include $<$ math.h $>$

main()

\{void *ptr;

int $\mathrm{gd}=$ DETECT, gm; 


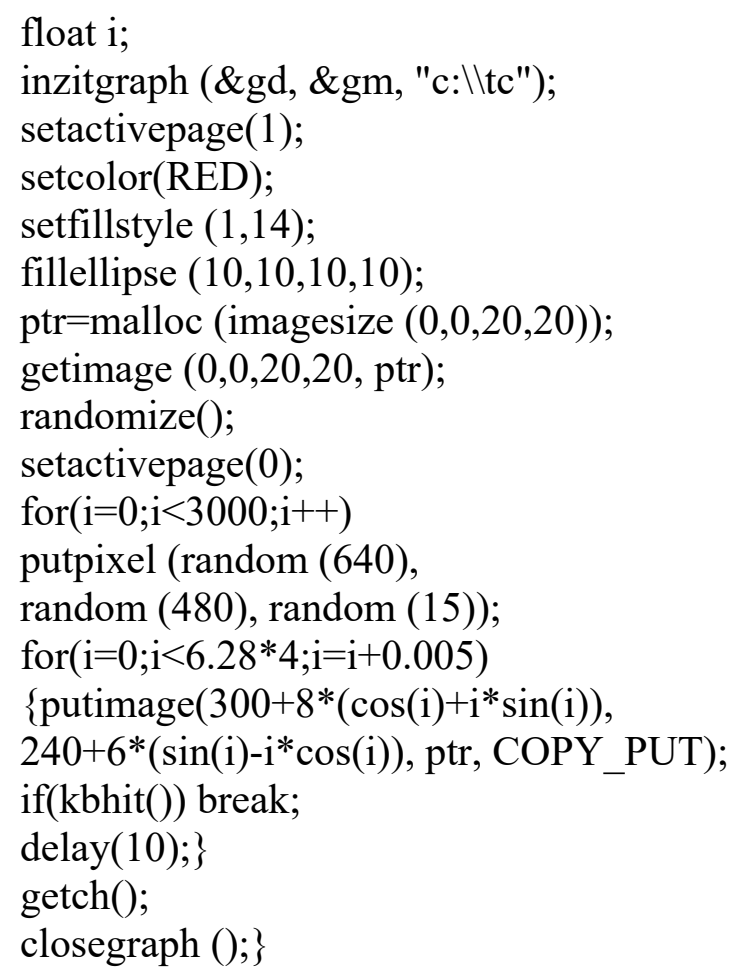

\subsection{Constantly Improves the Learning Difficulty, and the Students are Satisfied}

When learning the for loop statement, we first display the program, which uses the for statement of the bold part of the program to achieve animation. In order to deepen the students' understanding of the three expressions in the for loop, we first change the expression one, The original $i=0$ is changed to $\mathrm{i}=13$, and the result of the animation is shown in Fig.5 (B). This changes the initial position of the animation, so that the student knows that the expression 1 determines the initial position of the program; then we restore the expression one. The value changes the value of expression two, and $\mathrm{i}<6.28 * 4$ is changed to $\mathrm{i}<6.28 * 2$. The result of the animation is shown in Fig. 5 (C). The running result is two times less than the original, and the second expression determines the termination of the operation. Position; finally we change the expression three $i=i+0.005$, change 0.005 to 0.001 , the runtime can find that the animation running track is slower than the original, and fine, then we explain to the students that the increase of $i$ after each execution of the for loop The value is small, compared with the original, the number of times the final value loop is reached increases, so the animation running track becomes slower and thinner.

\section{Conclusion}

This paper starts from the research idea of "guided practice by theory and practice theory of argumentation", and combines the ARCS motivation design pattern with the teaching practice of computer public courses in higher vocational colleges. Firstly, the related theories of learning motivation are expounded through literature research, and the elements and design steps of the ARCS motivation model are analyzed. A series of ARCS motivation strategies are designed according to the motivation status of college students and the characteristics of computer public courses. The ARCS motivation strategy is applied in practice teaching. Through various evaluations, it is tested whether the proposed ARCS motivation strategy can stimulate students' motivation and improve. The academic level of the students and the quality of the teaching of the teachers. 


\section{References}

[1]. Xiang Tao, Zhou Mingqiang. Exploration of College Graduates' Motivation of Joining the Party Based on the Principle of Motivation Psychology. Journal of Inner Mongolia Normal University, Vol. 6(2016) No.45, p. 77-80.

[2]. Mao Minmin. Design and implementation of computer aided teaching aid system in colleges and universities. Southwest Jiaotong University, Vol. 1(2013) No.7, p.130-133.

[3]. Wang Libin, Li Aihua, He Qin, et al. Research and Practice of Computer-based Teaching Model Based on Task-Driven Medical University. E-commerce, Vol. 10(2011) No.17, p.76-79.

[4]. Zhang Shuo. Promoting the Mental Health of Students under the Cooperative Education Program in Chinese and Foreign Universities from the Perspective of Stimulating Learning Motivation. Educational Review, Vol.4(2015) No.11, p.59-63.

[5]. He Qing. On the Significance of Offering Game Design Courses in Computer Majors in Colleges and Universities. Electronic World, Vol. 3(2017) No.12, p.149-153.

[6]. LUO Guo-feng. Analysis on the Motivation of Computer Courses for College Students., Vol.11(2014) No.32, p.137-139. 